\title{
Surface Tension and Density of Liquid Hot Work Tool Steel W360 by voestalpine BÖHLER Edelstahl GmbH \& Co KG Measured with an Electromagnetic Levitation Apparatus
}

\author{
Thomas Leitner $^{1}$ (D) Anna Werkovits ${ }^{1}$ (D) . Siegfried Kleber ${ }^{2}$. \\ Gernot Pottlacher ${ }^{1}$ (D)
}

Received: 9 October 2020 / Accepted: 22 October 2020 / Published online: 28 December 2020

(c) The Author(s) 2020

\begin{abstract}
W360 is a hot work tool steel produced by voestalpine BÖHLER Edelstahl GmbH \& Co KG, a special steel producer located in Styria, Austria. Surface tension and density of liquid W360 were studied as a function of temperature in a non-contact, containerless fashion using the oscillating drop method inside an electromagnetic levitation setup. For both, surface tension and density, a linear model was adapted to present the temperature dependence of these measures, including values for the uncertainties of the fit parameters found. The data obtained are compared to pure iron (with $91 \mathrm{wt} \%$ the main component of W360), showing an overlap for the liquid density while there is a significant difference in surface tension $(-5.8 \%$ at the melting temperature of pure iron of $1811 \mathrm{~K}$ ).
\end{abstract}

Keywords Density · Electromagnetic levitation · Hot work tool steel · Liquid steel · Surface tension $\cdot$ W360

Electronic supplementary material The online version of this article (https://doi.org/10.1007/s1076 5-020-02765-X) contains supplementary material, which is available to authorized users.

Thomas Leitner

thomas.leitner@tugraz.at

Gernot Pottlacher

pottlacher@tugraz.at

Anna Werkovits

anna.werkovits@tugraz.at

Siegfried Kleber

siegfried.kleber@voestalpine.com

1 Institute of Experimental Physics, Graz University of Technology, NAWI Graz, Petersgasse 16, 8010 Graz, Austria

2 voestalpine BÖHLER Edelstahl GmbH \& Co KG, Mariazellerstraße 25, 8605 Kapfenberg, Austria 


\section{Introduction}

Surface tension and density (among other thermophysical properties) of liquid metals and alloys have gained more and more interest in the recent past, especially by industry, due to the fast and exciting developments in novel manufacturing techniques, like additive manufacturing (AM). The process-parameters of these new techniques, like for selective laser melting, are still unknown or not yet optimized for many materials and thus, simulations are performed using experimental surface tension and density data to calculate and test the process-parameters for new materials to improve the processes. But not only the new manufacturing techniques struggle with unknown materials' thermophysical properties, they already come into play one step before, e.g., when simulating the process of atomization, which is used to create suitable powders from alloys and steels for AM applications. Therefore, highquality experimental data of surface tension and density are strongly demanded for various alloys and steels. voestalpine BÖHLER Edelstahl GmbH \& Co KG (hereinafter shortly referred as BÖHLER), continuously extending their product-portfolio of their brand for additive manufacturing powder (Böhler AMPO), was therefore interested in the surface tension and density of their hot work tool steel W360.

But measuring the surface tension and density of liquid metals and alloys is a challenging task, due to the high melting temperatures and chemical reactivity at high temperatures of the material. At the Institute of Experimental Physics (IEP) of Graz University of Technology (TU Graz), we therefore use an electromagnetic levitation (EML) setup to ensure contact- and containerless conditions throughout the whole experiment. The sample is levitated freely in space, only environed by an inert gas atmosphere; thus, chemical reactions or interactions with the environment are almost completely suppressed.

\section{Materials and Methods}

This section provides a brief overview of the measurement method and data evaluation. For a more profound description of EML and the oscillating drop (OD) method in general and the electromagnetic levitation setup at TU Graz in particular, the interested reader is referred to the publications [1] and [2-6] since this information would go beyond the scope of this paper.

\subsection{Electromagnetic Levitation (EML) and Oscillating Drop (OD) Method}

In an EML apparatus, the electroconductive sample is levitated freely in space by applying an inhomogeneous, radio-frequency $(350 \mathrm{kHz})$ electromagnetic field to the sample, which exerts a Lorentz force on it that acts as a lifting force against gravitational force. Due to the ohmic losses of the induced eddy currents in the sample, it 
is simultaneously heated inductively. The electromagnetic field is formed by a twopart levitation coil (bottom- and upper-part, which are oppositely wound) that acts as inductance $L$ and together with a capacitance $C$ forms an oscillating circuit $(L C)$, which is fed by a high-frequency generator.

Levitation ensures contact- and containerless conditions for the measurement since the sample is only environed by an inert gas atmosphere. This is beneficial over contact-based measurement methods where measurements may get falsified due to reactions or interactions of the highly reactive metallic melt with its environment (e.g., crucible).

\subsubsection{Surface Tension Evaluation}

After the solid-liquid phase transition is undergone, the materials' surface tension tries to minimize the surface of the sample and forms a droplet on which surface oscillations (wobbling) can be observed. As the surface tension acts as restoring force against the deformation, the angular frequency of the surface oscillations depends on the surface tension of the material, which is described by the equation of Lord Rayleigh used in the OD method. The surface oscillations' angular frequency $\omega_{\mathrm{R}}$ (also called Rayleigh frequency) of the liquid droplet of mass $M$ depends on the materials surface tension $\gamma$ via [7]:

$$
\omega_{\mathrm{R}}^{2}=\frac{32 \pi}{3} \frac{\gamma}{M}
$$

Since the Rayleigh equation is only valid for a force-free, spherical droplet, the Cummings and Blackburn [8] correction must be applied for terrestrial conditions where the gravitational and levitation force act on the sample and lead to a distortion from ideal sphericity to a droplet-shaped sample. This requires the identification of the frequencies of the samples' oscillation modes from a frequency spectrum of the samples' radii. To obtain that, the samples' oscillations and shape are recorded by high-speed cameras and the video frames are subsequently analyzed using an edgedetection algorithm. This gives the time dependency of the radii which is then further used to generate the frequency spectrum by Fourier transforming the data.

\subsubsection{Density Evaluation}

To determine the samples' density, a shadowgraph video (side view) of the sample is recorded using a high-speed camera. For each frame of the video, the threedimensional volume of the sample is deduced from the two-dimensional side view by assuming vertical axis symmetry of the sample. Together with the weighed mass, the density of the sample is obtained. 
Table 1 Chemical composition of W360 in percentage by weight (wt\%)

\begin{tabular}{lllllll}
\hline Steel & \multicolumn{6}{l}{ Chemical composition/wt\% } \\
\cline { 2 - 7 } & $\mathrm{C}$ & $\mathrm{Si}$ & $\mathrm{Mn}$ & $\mathrm{Cr}$ & $\mathrm{Mo}$ & $\mathrm{V}$ \\
\hline W360 & 0.50 & 0.20 & 0.25 & 4.50 & 3.00 & 0.55 \\
\hline
\end{tabular}

Data have been taken from the product website of voestalpine BÖHLER Edelstahl GmbH \& Co KG [10]

\subsubsection{Temperature Evaluation}

For contactless temperature measurement, a single-wavelength pyrometer ${ }^{1}$ is used. To determine the true sample temperature, the normal spectral emissivity $\varepsilon$ of the material at the pyrometer wavelength $\lambda$ is needed. For that, a reference temperature $T_{\text {ref. }}$ (e.g., melting temperature) must be known at which the normal spectral emissivity $\varepsilon$ can be calibrated by identifying this temperature reading $T_{\text {read.@ } T_{\text {ref. }}}$ in the recorded temperature-time profile of the uncalibrated pyrometer $(\varepsilon=1)$. The following equation based on the Wien approximation is used (with the speed of light $c$, Planck constant $h$ and Boltzmann constant $k$ ) [9]:

$$
\varepsilon=\exp \left(\frac{c h}{k \lambda}\left(\frac{1}{T_{\text {ref. }}}-\frac{1}{T_{\text {read.@ } T_{\text {ref. }}}}\right)\right) .
$$

Consequently, a constant emissivity ( $\varepsilon=$ const.) in the liquid phase must be assumed so that the true temperature $T$ of an arbitrary temperature reading $T_{\text {read. }}$ can be calculated using [9]:

$$
T=\left(\frac{1}{T_{\text {read. }}}+\frac{k \lambda}{c h} \ln (\varepsilon)\right)^{-1} .
$$

By inserting (2) into (3), the expression for the true temperature $T$ can be finally simplified to:

$$
T=\left(\frac{1}{T_{\text {read. }}}+\frac{1}{T_{\text {ref. }}}-\frac{1}{T_{\text {read. } @ T_{\text {ref. }}}}\right)^{-1} .
$$

\subsection{Hot Work Tool Steel W360}

The composition of the hot work tool steel W360 by voestalpine BÖHLER Edelstahl GmbH \& Co KG is stated in Table 1.

It is characterized by high hardness, exceptional toughness, high temper resistance, good thermal conductivity, ability to be water cooled and a homogeneous

\footnotetext{
${ }^{1}$ LumaSense Technologies IMPAC IGA6 Advanced: spectral range of $1.45 \mu \mathrm{m}$ to $1.80 \mu \mathrm{m}$.
} 
Table 2 Liquidus and solidus temperatures of W360 provided by BÖHLER from differential scanning calorimetry (DSC), performed at the Chair of Ferrous Metallurgy, Montanuniversität Leoben (MUL)

\begin{tabular}{lll}
\hline & $/{ }^{\circ} \mathrm{C}$ & $/ \mathrm{K}$ \\
\hline$T_{\mathrm{L}}$ & 1475.9 & 1749.1 \\
$T_{\mathrm{S}}$ & 1385.8 & 1659.0 \\
\hline
\end{tabular}

$T_{\mathrm{L}}$ is the liquidus temperature and $T_{\mathrm{S}}$ is the solidus temperature

The uncertainty of both, liquidus and solidus temperature is stated with $\pm 1.5 \mathrm{~K}$ [11]; more details on the DSC setup used (NETZSCH DSC 404 F1 Pegasus) as well as the measurement method and procedure applied at MUL can be found in [11,12]

microstructure. Typical fields of application and use are among others: dies and punches in warm and hot forging, tooling for high-speed presses, toughness-critical cold work applications, etc. [10]

Since the additive manufacturing of parts for the applications listed is getting more and more important, voestalpine BÖHLER Edelstahl GmbH \& Co KG recently extended their portfolio for additive manufacturing powders (Böhler AMPO) with W360 AMPO.

As elaborated in Sect. 2.1, the emissivity of the pyrometer must be calibrated to be able to determine the true sample temperature. For this calibration, the liquidus and/or solidus temperatures are needed for the material under investigation since those reference temperatures can be easily assigned in the temperature-time curve. The differential scanning calorimetry (DSC) measurements of liquidus and solidus temperatures denoted in Table 2 have been provided by BÖHLER.

\subsection{Sample Preparation and Experimental Parameters}

All W360 samples were polished using an abrasive paper (grade 480) to remove any surface oxidation and were cleaned in isopropanol in an ultrasonic bath before they were inserted into the EML processing chamber. Each sample was weighed before and after the experiment to quantify the mass loss due to evaporation of sample material.

After inserting the samples into the vented processing chamber, the pressure was reduced to the $10^{-6} \mathrm{mbar}$ regime to remove as much oxygen as possible. For the experiments, the chamber was then refilled with a mixture of the inert gases argon and helium which was slightly enriched with hydrogen to prevent oxide formation due to residual oxygen in the processing chamber or residual oxygen impurities in the processing gas. The gases used were: ARCAL $10^{2}$ and a custom gas mixture $\mathrm{CGM}^{3}$, which are further filtered by an AirLiQuide ALPHAGAZ O2-FREE purification

\footnotetext{
${ }^{2}$ Air Liquide ARCAL 10: $\mathrm{Ar}+2.4$ vol $\% \mathrm{H}_{2}$.

${ }^{3}$ Air Liquide CGM: $\mathrm{He}+3.83 \mathrm{vol} \% \mathrm{H}_{2}$.
} 


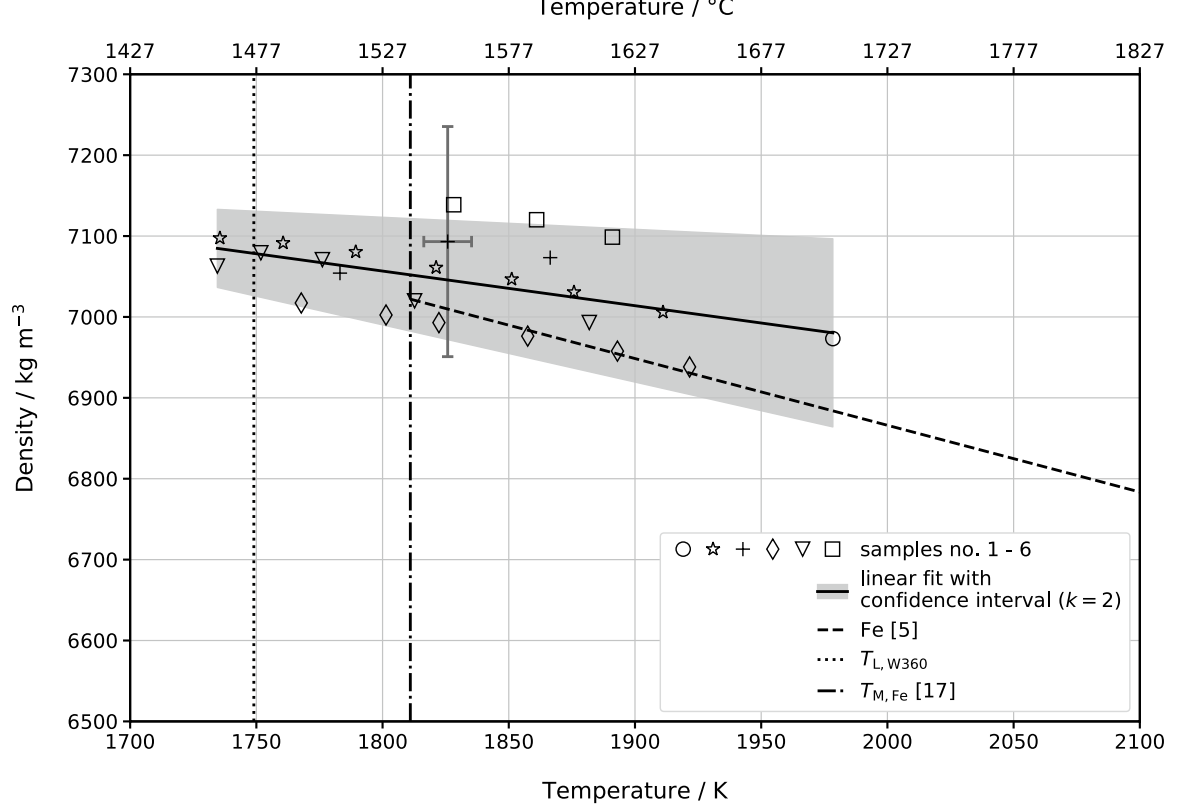

Fig. 1 Measurement results of density as a function of temperature of W360. The raw data can be found in Appendix 2, Table 6. For better readability, the measurement uncertainty is plotted only for a single datapoint. To represent the temperature dependence of the density of liquid W360, the linear model (5) was adapted to the data (solid black line). The resulting fit parameters are listed in Table 3. For comparison, reference data [5] of pure iron (with $91 \mathrm{wt} \%$ the main component of W360) is shown as dashed line. For temperature reference, the liquidus temperature of W360 $T_{\mathrm{L}, \mathrm{W} 360}$ (see Table 2) and the melting temperature of pure iron $T_{\mathrm{M}, \mathrm{Fe}}[17]$ are plotted as dotted and dash-dot lines

system that lowers the oxygen content from the one-digit ppm down to the one-digit ppb range.

\section{Results}

Surface tension and density of liquid W360 were measured over a temperature range of about $200 \mathrm{~K}$, starting slightly below the liquidus temperature in the undercooled regime.

The raw data (individual datapoints) for density and surface tension of each sample are listed in Appendix 2, Table 6 and are additionally supplied online as supplementary CSV file.

In total, six samples were processed while the mass of the samples ranged from $420 \mathrm{mg}$ to $438 \mathrm{mg}$. The maximum mass loss for a single sample observed was $6.6 \mathrm{mg}(\hat{=} 1.6 \%)$ while the typical mass loss was in the range of $0.6 \%$. 
Table 3 Density fit parameters according to model (5)

\begin{tabular}{lllll}
\hline Material & $\rho_{\mathrm{L}} / \mathrm{kg} \mathrm{m}^{-3}$ & $\frac{\partial \rho}{\partial T} / \mathrm{kg} \mathrm{m}^{-3} \mathrm{~K}^{-1}$ & $T_{\mathrm{L}} / \mathrm{K}$ & Refs. \\
\hline W360 & $7079 \pm 48$ & $-0.428 \pm 0.462$ & 1749.1 & This study \\
Fe & 7022 & -0.835 & $1811[17]$ & {$[5]$} \\
\hline
\end{tabular}

$\rho_{\mathrm{L}}$ is the density at the liquidus temperature, $\frac{\partial \rho}{\partial T}$ is the change of density with temperature, $T_{\mathrm{L}}$ is the liquidus temperature and Refs. is the literature reference

Please note that an additional (insignificant) digit is provided for the slope $\frac{\partial \rho}{\partial T}$ of W360 so that the original model curve is reproducible

\subsection{Density}

Figure 1 shows the results of the density measurements. For comparison, Fig. 1 also contains reference data for the liquid density of pure iron ${ }^{4}$, as pure iron is the main component of W360 with a mass fraction of $91 \%$.

The linear model (5) was adapted to all measurement data obtained to describe the liquid density of W360 as a function of temperature $\rho(T)$ :

$$
\rho(T)=\rho_{\mathrm{L}}+\frac{\partial \rho}{\partial T}\left(T-T_{\mathrm{L}}\right)
$$

In (5), $\rho_{\mathrm{L}}$ is the density at the liquidus temperature $T_{\mathrm{L}}$ and $\frac{\partial \rho}{\partial T}$ describes the change of the liquid density with temperature $T$.

Compared to pure iron (which is the main component of W360) the liquid density of W360 is slightly higher $\left(+30 \mathrm{~kg} \mathrm{~m}^{-3} \hat{=}+0.4 \%\right.$ at the melting temperature of pure iron of $1811 \mathrm{~K}$ ). The (negative) change of density with temperature $\frac{\partial \rho}{\partial T}$ of W360 is lower than for pure iron.

Table 3 summarizes the liquid density fit parameters according to the linear model (5) as well as comparison data of pure iron as plotted in Fig. 1.

\subsection{Surface Tension}

The measurement results for surface tension of liquid W360 are shown in Fig. 2, together with reference data of pure iron [5] for comparison.

To describe the surface tension of liquid W360 as a function of temperature $\gamma(T)$, the linear model (6) was adapted to all measurement data obtained:

\footnotetext{
${ }^{4}$ Fit parameter obtained by Leitner et al. [5] by building the mean of the single $\rho_{\mathrm{L}}$ and $\frac{\partial \rho}{\partial T}$ results from [13-16].
} 


\section{Temperature $/{ }^{\circ} \mathrm{C}$}

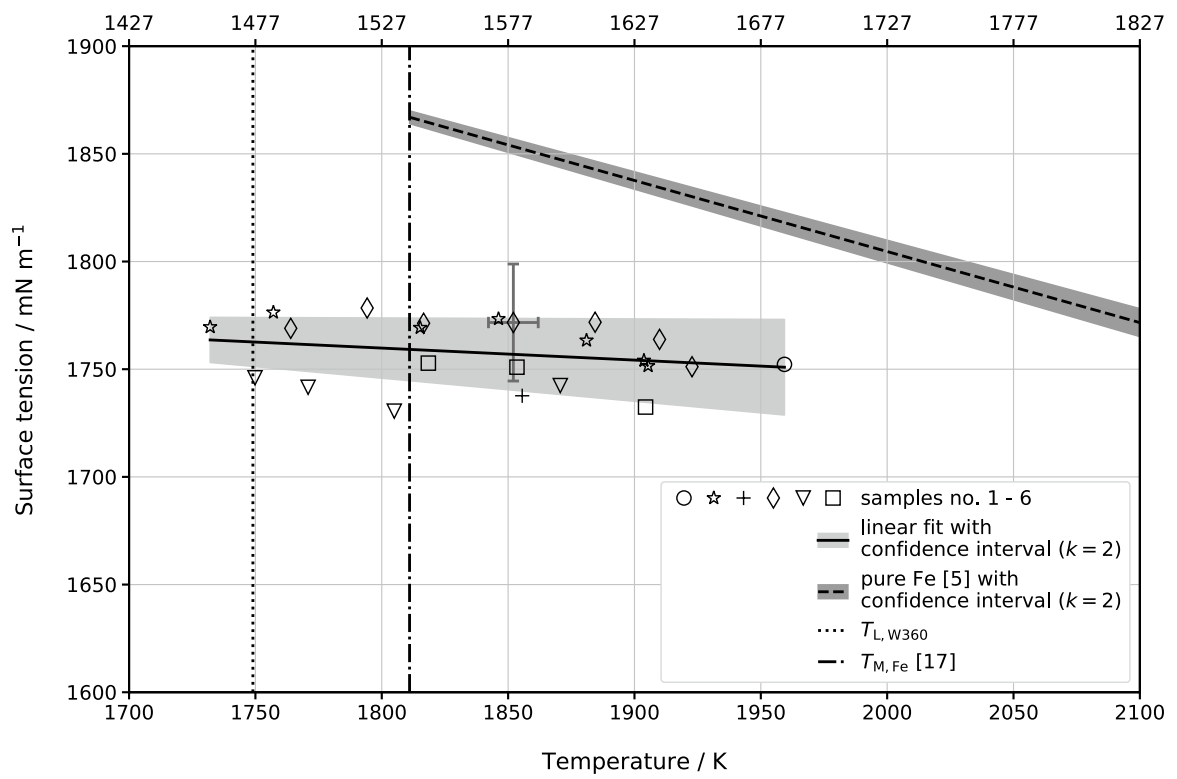

Fig. 2 Measurement results of surface tension as a function of temperature of W360. The raw data are listed in Appendix 2, Table 6. The measurement uncertainty is plotted only for a single datapoint to enhance the readability of the graph. The linear model (6) was adapted to the measured data to represent the temperature dependence of surface tension (solid black line). The model parameters found in the fitting process are listed in Table 4. As reference, the surface tension of pure iron (with $91 \mathrm{wt} \%$ the main component of W360) is shown as dashed line. For temperature reference, the liquidus temperature of $\mathrm{W} 360 T_{\mathrm{L}, \mathrm{W} 360}$ (see Table 2) and the melting temperature of pure iron $T_{\mathrm{M}, \mathrm{Fe}}[17]$ are plotted as dotted and dash-dot lines

Table 4 Surface tension fit parameters according to model (6)

\begin{tabular}{lllll}
\hline Material & $\gamma_{\mathrm{L}} / \mathrm{mN} \mathrm{m}^{-1}$ & $\frac{\partial \gamma}{\partial T} / \mathrm{mN} \mathrm{m}^{-1} \mathrm{~K}^{-1}$ & $T_{\mathrm{L}} / \mathrm{K}$ & Refs. \\
\hline W360 & $1763 \pm 10$ & $-0.056 \pm 0.093$ & 1749.1 & This study \\
Fe & 1867 & -0.33 & $1811[17]$ & {$[5]$} \\
\hline
\end{tabular}

$\gamma_{\mathrm{L}}$ is the surface tension at the liquidus temperature, $\frac{\partial \gamma}{\partial T}$ is the change of surface tension with temperature, $T_{\mathrm{L}}$ is the liquidus temperature and Refs. is the literature reference

Please note that an additional (insignificant) digit is provided for the slope $\frac{\partial \gamma}{\partial T}$ of W360, so that the original model curve is reproducible

$$
\gamma(T)=\gamma_{\mathrm{L}}+\frac{\partial \gamma}{\partial T}\left(T-T_{\mathrm{L}}\right)
$$

In (6), $\gamma_{\mathrm{L}}$ denotes the surface tension at the liquidus temperature $T_{\mathrm{L}}$ and $\frac{\partial \gamma}{\partial T}$ describes the change of the liquid surface tension with temperature $T$. 
When compared to pure iron, the obtained surface tension of W360 is lower in both, the slope $\frac{\partial \gamma}{\partial T}$ and the liquidus temperature intersection $\gamma_{\mathrm{L}}\left(-108 \mathrm{mN} \mathrm{m}^{-1} \hat{=}\right.$ $-5.8 \%$ at the melting temperature of pure iron of $1811 \mathrm{~K}$ ).

Table 4 summarizes the surface tension fit parameters according to the linear model (6) as well as comparison data of pure iron as plotted in Fig. 2.

\section{Uncertainties}

The uncertainty analysis was performed according to the "Guide to the expression of uncertainty in measurement", or shortly referred as "GUM" [18]. Uncertainties stated are expanded uncertainties at a $95 \%$ confidence level (coverage factor $k=2$ ).

The fit coefficients of the models (5) and (6) were calculated following the guide by Matus [19] so that the abscissa and ordinate uncertainties of the individual datapoints are accounted for.

For details on the uncertainty budget of the levitation setup at TU Graz, we refer to the publications $[2,3,20]$ which include an in-depth description of this topic.

As suggested in our latest publication [6], we meanwhile improved our qualitative mass-loss model to interpolate the sample mass at the video acquisition times. In the past, a simple linear interpolation between the weighed mass at the start and the end of the experiment was used, which did not take the temperature-time profile into account. In [6], we presented a qualitative estimate to interpolate the mass for a given time $m_{i}\left(t_{i}\right)$ that accounts for the temperature-time profile. The idea was to map the total mass loss $m_{\text {loss }}$ to the time-integral of the temperature-time profile between start $\left(t_{\mathrm{s}}\right.$, melting) and end $\left(t_{\mathrm{e}}\right.$, solidification) of the experiment. The mass at a given time $m_{i}\left(t_{i}\right)$ is then calculated by:

$$
m_{i}\left(t_{i}\right)=m_{\mathrm{s}}-\frac{\int_{t_{\mathrm{s}}}^{t_{\mathrm{i}}} T \mathrm{~d} t}{\int_{t_{\mathrm{s}}}^{t_{\mathrm{e}}} T \mathrm{~d} t} m_{\mathrm{loss}} .
$$

If the temperature variation is small compared to the average temperature during the experiment, the model is (almost) linear in time. To enhance the temperature sensitivity of the model, it was modified so that the minimum temperature $\left(T_{\min }\right)$ observed during the experiment is subtracted before the integral is calculated:

$$
m_{i}\left(t_{i}\right)=m_{\mathrm{s}}-\frac{\int_{t_{\mathrm{s}}}^{t_{\mathrm{i}}}\left(T-T_{\mathrm{min} .}\right) \mathrm{d} t}{\int_{t_{\mathrm{s}}}^{t_{\mathrm{e}}}\left(T-T_{\text {min. }}\right) \mathrm{d} t} m_{\mathrm{loss}} .
$$

Sample no. 6 unfortunately exited the stable levitation position while liquid, which is why it could not be caught and weighed after the experiment. The data evaluation for sample no. 6 was therefore performed by estimating the mass at the end of the experiment as a function of the temperature-time profile based on the typical relative mass loss of the samples no. 1 to 5 and the precedent try-out samples. 


\section{Conclusion}

Surface tension and density of liquid W360 steel were studied in a non-contact, containerless fashion using the oscillating drop method in combination with an electromagnetic levitation setup.

The temperature-dependent density of liquid W360 can be described by the linear model (5) with the fit parameters from Table 3. Thus, uncertainty of the calculated density ranges from $0.7 \%$ at the liquidus temperature $T_{\mathrm{L}}$ of $1749 \mathrm{~K}$ to $1.5 \%$ at $T_{\mathrm{L}}+$ $200 \mathrm{~K}$.

Surface tension and its temperature dependence of W360 are described by the linear model (6) together with the respective fit parameters from Table 4 . The uncertainty of the calculated surface tension using the said model and parameters ranges from $0.7 \%$ at $T_{\mathrm{L}}$ to $1.2 \%$ at $T_{\mathrm{L}}+200 \mathrm{~K}$.

As there are no reference data available for this particular steel in the literature, reference data for pure iron were presented for comparison since this is the main component of W360 with a mass fraction of $91 \%$.

When compared to pure iron, the liquid density of W360 at the melting temperature of pure iron $(1811 \mathrm{~K})$ is greater by only $+30 \mathrm{~kg} \mathrm{~m}^{-3}(+0.4 \%)$, the negative slope (change of density with temperature) is less steep. In fact, the data of the liquid density of W360 and pure iron overlap within measurement uncertainty.

The surface tension results of W360 not only show lower values compared to pure iron $\left(-108 \mathrm{mN} \mathrm{m}^{-1} \hat{=}-5.8 \%\right.$ at the melting temperature of pure iron of $1811 \mathrm{~K})$, but also show a lower temperature dependence. The change of surface tension with temperature is only $-0.056 \mathrm{mN} \mathrm{m}^{-1} \mathrm{~K}^{-1}$ (pure iron: $-0.33 \mathrm{mN} \mathrm{m}^{-1} \mathrm{~K}^{-1}$ ).

Acknowledgments The work was funded by the Austrian Research Promotion Agency (FFG), Project "Surfacetension-Steel" (Project No. 855678). We further thank Dr. Peter Presoly from the Chair of Ferrous Metallurgy, Montanuniversität Leoben, for supplying information on the measurement uncertainty of the liquidus and solidus temperatures.

Funding Open access funding provided by Graz University of Technology..

\section{Compliance with Ethical Standards}

Conflicts of interest The authors declare that they have no conflict of interest.

Open Access This article is licensed under a Creative Commons Attribution 4.0 International License, which permits use, sharing, adaptation, distribution and reproduction in any medium or format, as long as you give appropriate credit to the original author(s) and the source, provide a link to the Creative Commons licence, and indicate if changes were made. The images or other third party material in this article are included in the article's Creative Commons licence, unless indicated otherwise in a credit line to the material. If material is not included in the article's Creative Commons licence and your intended use is not permitted by statutory regulation or exceeds the permitted use, you will need to obtain permission directly from the copyright holder. To view a copy of this licence, visit http://creativecommons.org/licen ses/by/4.0/. 


\section{Appendix}

\section{Tabular Data of Temperature-Dependent Surface Tension and Density of W360}

For the reader's convenience, Table 5 lists the density and surface tension of W360 for different temperatures in steps of $10 \mathrm{~K}$, calculated from the model equations (5) and (6) with their respective fit parameters listed in Tables 3 and 4.

Table 5 Exemplary data points of obtained density and surface tension linear fits with corresponding uncertainties

\begin{tabular}{|c|c|c|c|c|c|}
\hline $\begin{array}{l}T / \\
\mathrm{K}\end{array}$ & $\begin{array}{l}\mathrm{T} / \\
{ }^{\circ} \mathrm{C}\end{array}$ & $\begin{array}{l}\rho / \\
\mathrm{kg} \mathrm{m}^{-3}\end{array}$ & $\begin{array}{l}\Delta \rho / \\
\mathrm{kg} \mathrm{m}^{-3}\end{array}$ & $\begin{array}{l}\gamma / \\
\mathrm{mN} \mathrm{m}^{-1}\end{array}$ & $\begin{array}{l}\Delta \gamma / \\
\mathrm{mN} \mathrm{m}^{-1}\end{array}$ \\
\hline 1730 & 1457 & 7087 & 49 & 1764 & 11 \\
\hline 1740 & 1467 & 7082 & 48 & 1763 & 10 \\
\hline $1749\left(T_{\mathrm{L}}\right)$ & 1476 & 7079 & 48 & 1763 & 10 \\
\hline 1750 & 1477 & 7078 & 48 & 1763 & 10 \\
\hline 1760 & 1487 & 7074 & 48 & 1762 & 10 \\
\hline 1770 & 1497 & 7070 & 49 & 1761 & 11 \\
\hline 1780 & 1507 & 7065 & 50 & 1761 & 11 \\
\hline 1790 & 1517 & 7061 & 51 & 1760 & 11 \\
\hline 1800 & 1527 & 7057 & 53 & 1760 & 11 \\
\hline 1810 & 1537 & 7052 & 55 & 1759 & 12 \\
\hline 1820 & 1547 & 7048 & 58 & 1759 & 12 \\
\hline 1830 & 1557 & 7044 & 61 & 1758 & 13 \\
\hline 1840 & 1567 & 7040 & 64 & 1758 & 13 \\
\hline 1850 & 1577 & 7035 & 67 & 1757 & 14 \\
\hline 1860 & 1587 & 7031 & 70 & 1756 & 15 \\
\hline 1870 & 1597 & 7027 & 74 & 1756 & 15 \\
\hline 1880 & 1607 & 7022 & 77 & 1755 & 16 \\
\hline 1890 & 1617 & 7018 & 81 & 1755 & 17 \\
\hline 1900 & 1627 & 7014 & 85 & 1754 & 18 \\
\hline 1910 & 1637 & 7010 & 88 & 1754 & 18 \\
\hline 1920 & 1647 & 7005 & 92 & 1753 & 19 \\
\hline 1930 & 1657 & 7001 & 96 & 1753 & 20 \\
\hline 1940 & 1667 & 6997 & 100 & 1752 & 21 \\
\hline 1950 & 1677 & 6993 & 104 & 1751 & 21 \\
\hline 1960 & 1687 & 6988 & 109 & 1751 & 22 \\
\hline 1970 & 1697 & 6984 & 113 & 1750 & 23 \\
\hline
\end{tabular}

$T$ is the temperature, $\rho$ is the density, $\Delta \rho$ is the expanded uncertainty of density, $\gamma$ is the surface tension and $\Delta \gamma$ is the expanded uncertainty of surface tension

The liquidus temperature $T_{\mathrm{L}}$ of W360 is highlighted in the table 


\section{Raw Measurement Data}

Table 6 lists all individual data points of all experiments (raw data) that were used for the data analysis presented in the main text. The data are also available as supplementary CSV file online.

Please note that an insignificant digit was added so that the fit parameters found in Tables 3 and 4 can be reproduced from this tabular data.

Table 6 Raw data

\begin{tabular}{|c|c|c|c|c|c|c|}
\hline No. & $\begin{array}{l}T / \\
\mathrm{K}\end{array}$ & $\begin{array}{l}\Delta T / \\
\mathrm{K}\end{array}$ & $\begin{array}{l}\rho / \\
\mathrm{kg} \mathrm{m}^{-3}\end{array}$ & $\begin{array}{l}\Delta \rho / \\
\mathrm{kg} \mathrm{m}^{-3}\end{array}$ & $\begin{array}{l}\gamma / \\
\mathrm{mN} \mathrm{m}^{-1}\end{array}$ & $\begin{array}{l}\Delta \gamma / \\
\mathrm{mN} \mathrm{m}^{-1}\end{array}$ \\
\hline \multirow[t]{2}{*}{1} & 1959.4 & 11.2 & - & - & 1752.2 & 27.5 \\
\hline & 1978.4 & 43.3 & 6973.2 & 140.4 & - & - \\
\hline \multirow[t]{14}{*}{2} & 1732.1 & 8.6 & - & - & 1769.6 & 27.0 \\
\hline & 1735.6 & 8.6 & 7097.4 & 142.4 & - & - \\
\hline & 1757.1 & 8.7 & - & - & 1776.4 & 27.1 \\
\hline & 1760.6 & 8.9 & 7091.5 & 142.3 & - & - \\
\hline & 1789.4 & 9.2 & 7080.4 & 142.1 & - & - \\
\hline & 1815.2 & 9.3 & - & - & 1769.3 & 27.1 \\
\hline & 1821.2 & 9.3 & 7061.0 & 141.7 & - & - \\
\hline & 1846.2 & 9.6 & - & - & 1773.4 & 27.2 \\
\hline & 1851.2 & 9.7 & 7046.6 & 141.4 & - & - \\
\hline & 1875.8 & 9.9 & 7030.6 & 141.1 & - & - \\
\hline & 1881.0 & 10.1 & - & - & 1763.4 & 27.1 \\
\hline & 1903.7 & 17.5 & - & - & 1754.0 & 27.1 \\
\hline & 1905.4 & 10.4 & - & - & 1751.5 & 27.1 \\
\hline & 1911.1 & 10.3 & 7005.9 & 140.6 & - & - \\
\hline \multirow[t]{5}{*}{3} & 1783.1 & 11.5 & 7054.2 & 141.4 & - & - \\
\hline & 1820.3 & 10.1 & - & - & - & - \\
\hline & 1825.8 & 9.5 & 7093.1 & 142.2 & - & - \\
\hline & 1855.6 & 9.8 & - & - & 1737.7 & 27.4 \\
\hline & 1866.4 & 10.4 & 7073.3 & 141.9 & - & - \\
\hline \multirow[t]{13}{*}{4} & 1764.0 & 8.8 & - & - & 1769.0 & 27.1 \\
\hline & 1767.8 & 9.0 & 7017.3 & 140.7 & - & - \\
\hline & 1794.2 & 9.1 & - & - & 1778.4 & 27.2 \\
\hline & 1801.4 & 9.2 & 7002.4 & 140.4 & - & - \\
\hline & 1816.6 & 9.5 & - & - & 1771.3 & 27.1 \\
\hline & 1822.3 & 9.5 & 6993.0 & 140.2 & - & - \\
\hline & 1852.1 & 9.8 & - & - & 1771.7 & 27.2 \\
\hline & 1857.5 & 9.9 & 6976.3 & 139.9 & - & - \\
\hline & 1884.4 & 10.1 & - & - & 1771.8 & 27.2 \\
\hline & 1893.0 & 10.3 & 6957.8 & 139.5 & - & - \\
\hline & 1909.9 & 10.6 & - & - & 1763.8 & 27.1 \\
\hline & 1921.6 & 10.8 & 6938.2 & 139.2 & - & - \\
\hline & 1922.8 & 10.6 & - & - & 1751.1 & 27.1 \\
\hline
\end{tabular}


Table 6 (continued)

\begin{tabular}{|c|c|c|c|c|c|c|}
\hline No. & $\begin{array}{l}T / \\
\mathrm{K}\end{array}$ & $\begin{array}{l}\Delta T / \\
\mathrm{K}\end{array}$ & $\begin{array}{l}\rho / \\
\mathrm{kg} \mathrm{m}^{-3}\end{array}$ & $\begin{array}{l}\Delta \rho / \\
\mathrm{kg} \mathrm{m}^{-3}\end{array}$ & $\begin{array}{l}\gamma / \\
\mathrm{mN} \mathrm{m}^{-1}\end{array}$ & $\begin{array}{l}\Delta \gamma / \\
\mathrm{mN} \mathrm{m}^{-1}\end{array}$ \\
\hline \multirow[t]{9}{*}{5} & 1734.6 & 9.3 & 7062.9 & 141.6 & - & - \\
\hline & 1749.8 & 8.7 & - & - & 1746.0 & 27.6 \\
\hline & 1751.8 & 8.6 & 7079.3 & 141.9 & - & - \\
\hline & 1770.8 & 9.0 & - & - & 1741.6 & 27.5 \\
\hline & 1776.2 & 9.3 & 7070.8 & 141.7 & - & - \\
\hline & 1804.9 & 9.1 & - & - & 1730.5 & 27.5 \\
\hline & 1812.7 & 9.4 & 7019.9 & 140.7 & - & - \\
\hline & 1870.6 & 10.1 & - & - & 1742.4 & 27.6 \\
\hline & 1881.9 & 10.0 & 6993.1 & 140.2 & - & - \\
\hline \multirow[t]{6}{*}{6} & 1818.4 & 9.3 & - & - & 1752.8 & 27.1 \\
\hline & 1828.2 & 9.4 & 7138.7 & 143.1 & - & - \\
\hline & 1853.5 & 9.8 & - & - & 1750.9 & 27.1 \\
\hline & 1861.0 & 9.9 & 7120.2 & 142.8 & - & - \\
\hline & 1891.1 & 10.1 & 7098.7 & 142.4 & - & - \\
\hline & 1904.4 & 10.1 & - & - & 1732.4 & 27.0 \\
\hline
\end{tabular}

No. is the sample number, $T$ is the temperature, $\Delta T$ is the expanded uncertainty of temperature, $\rho$ is the density, $\Delta \rho$ is the expanded uncertainty of density, $\gamma$ is the surface tension and $\Delta \gamma$ is the expanded uncertainty of surface tension

\section{References}

1. I. Egry, H. Giffard, S. Schneider, Meas. Sci. Technol. 16(2), 426 (2005). https://doi. org/10.1088/0957-0233/16/2/013

2. K. Aziz, Surface tension measurements of liquid metals and alloys by oscillating drop technique in combination with an electromagnetic levitation device. Ph.D. thesis, Graz University of Technology (2016). http://diglib.tugraz.at/surface-tension-measurements-of-liquid-metals-and-alloys-by-oscil lating-drop-technique-in-combination-with-an-electromagnetic-levitation-device-2016

3. A. Schmon, Density determination of liquid metals by means of containerless techniques. Ph.D. thesis, Graz University of Technology (2016). http://diglib.tugraz.at/density-determination-of-liqui d-metals-by-means-of-containerless-techniques-2016

4. M. Leitner, T. Leitner, A. Schmon, K. Aziz, G. Pottlacher, Metall. Mater. Trans. A 48(6), 3036 (2017). https://doi.org/10.1007/s11661-017-4053-6

5. T. Leitner, O. Klemmer, G. Pottlacher, Tm-Tech. Mess. 84(12), 787 (2017). https://doi. org/10.1515/teme-2017-0085

6. A. Werkovits, T. Leitner, G. Pottlacher, High Temp. High Press. 49(1-2), 107 (2020). https://doi. org/10.32908/hthp.v49.855

7. L. Rayleigh, P. R. Soc. London 29(196-199), 71 (1879). https://doi.org/10.1098/rspl.1879.0015

8. D.L. Cummings, D.A. Blackburn, J. Fluid Mech. 224, 395 (1991). https://doi.org/10.1017/S0022 112091001817

9. F. Henning, Temperaturmessung (Springer. Berlin Heidelberg (1977). https://doi. org/10.1007/978-3-642-81138-8

10. voestalpine BÖHLER Edelstahl GmbH \& Co KG. product description BÖHLER W360 ISOBLOC (2020). https://www.bohler.at/app/uploads/sites/92/2020/02/productdb/api/w360de.pdf 
11. P. Presoly, R. Pierer, C. Bernhard, Metall. Mater. Trans. A 44(12), 5377 (2013). https://doi. org/10.1007/s11661-013-1671-5

12. M. Bernhard, P. Presoly, N. Fuchs, C. Bernhard, Y.B. Kang, Metall. Mater. Trans. A 51(10), 5351 (2020). https://doi.org/10.1007/s11661-020-05912-Z

13. J. Brillo, I. Egry, Z. Metallkd. 95(8), 691 (2004). https://doi.org/10.3139/146.018009

14. H. Kobatake, J. Brillo, J. Mater. Sci. 48(14), 4934 (2013). https://doi.org/10.1007/s10853-013-7274-0

15. A.V. Grosse, A.D. Kirshenbaum, J. Inorg. Nucl. Chem. 25(4), 331 (1963). https://doi. org/10.1016/0022-1902(63)80181-5

16. M. Watanabe, M. Adachi, H. Fukuyama, J. Mater. Sci. 51(7), 3303 (2015). https://doi. org/10.1007/s10853-015-9644-2

17. Landolt-Börnstein, in Pure Substances. Part 1: Elements and Compounds from AgBr to Ba3N2 (Springer Nature, 1999), pp. 25-50. https://doi.org/10.1007/10652891_5

18. Working Group 1 of the Joint Committee for Guides in Metrology (JCGM/WG 1), Evaluation of measurement data - Guide to the expression of uncertainty in measurement (JCGM - Joint Committee for Guides in Metrology, 2008). https:/www.bipm.org/utils/common/documents/jcgm/ JCGM_100_2008_E.pdf

19. M. Matus, Tm-Tech. Mess. 72(10/2005) (2005). https://doi.org/10.1524/teme.2005.72.10_2005.584

20. T. Leitner, Thermophysical properties of liquid aluminium determined by means of electromagnetic levitation. Master's thesis, Graz University of Technology (2016). https://diglib.tugraz.at/therm ophysical-properties-of-liquid-aluminium-determined-by-means-of-electromagnetic-levitation-2016

Publisher's Note Springer Nature remains neutral with regard to jurisdictional claims in published maps and institutional affiliations. 